\title{
Psychological and Sociological Factors Weakening Public Budget Awareness*
}

\author{
Fidan Kılavuz ${ }^{1}$ \\ Cihan Yüksel ${ }^{2}$
}

RESEARCH

ARTICLE

\section{ARTICLE INFO}

Submitted : 19.10 .2019

Revised : 05.11 .2019

Accepted : 15.11 .2019

Available : 30.12 .2019

iThenticate similarity

score: $16 \%$

JEL classification:

H31, H61, E71

Keywords:

Public Budget,

Common Wallet,

Behavioral Economics,

Fiscal Psychology,

Fiscal Sociology

\begin{abstract}
A B S T R A C T
Public budget, which is the total of the expenditures made to meet the common needs of the society and of the revenues obtained to finance these expenditures, can be expressed with a "common wallet" metaphor. However, the main problem is, in case that public resources are not used correctly and effectively, why citizens do not show as much sensitivity towards their common wallets, as they show towards their personal wallets. It is important to examine the factors that weaken public budget awareness (common wallet perception) on the basis of behavioral economics, which is an area that observes the effects of people's attitudes, behaviors, and thoughts on economic-based choices and decisions and examines these observations based on experiments. For this reason, the main purpose of our study has been to bring some concepts used in the fields of psychology and sociology in the field of public finance. In this study, the "fiscal alienation" concept was derived from the concept of lack of social belonging, "lack of fiscal altruistic punishment" concept from the concept of altruistic punishment, "fiscal bystander effect" from the concept of the bystander effect, "fiscal social loafing" concept from the concept of social loafing, "behavioral fiscal dissonance" concept from the concept of the theory of cognitive dissonance, and "the problem of fiscal ethic" concept from the concept of undeveloped ethical culture/behaviors.
\end{abstract}

Cite this article as: Kılavuz, F. \& Yüksel, C. (2019). "Psychological and Sociological Factors Weakening Public Budget Awareness", International Journal of Public Finance, 4(2), 127-144.

\footnotetext{
* This study is an expanded version of the papers presented at the 34th International Public Finance Conference / Turkey on 24-27 April 2019.

1 Master of Public Finance, ORCID: 0000-0002-7772-4782, Mersin University, Department of Public Finance, Turkey, klavuzfidan@yahoo.com

2 Asst. Prof. Dr., ORCID: 0000-0003-1959-1245, Mersin University, Department of Public Finance, Turkey, cihanyuksel@mersin.edu.tr
} 


\section{Introduction}

Public budget, which is one of the most important instruments of the public sector, is a fiscal planning tool that includes public revenues and expenditures. The public budget is formed by the participation of citizens in a number of co-finances, particularly taxes. Public expenditures, or in other words the common expenditures of the society are financed by these budgetary resources created by the co-financing of citizens. The fact that the common expenditures are financed by the public budget, which is shaped by the co-financing, is one of the main pillars of that the public budget is actually the common wallet of all citizens living in that country. As a matter of fact, just like individuals' personal budgets (personal wallets) that represent their personal income and expenses, there may be a public budget (common wallet) that represents the common income and expenses of the society. In our study, we have expressed the citizens' sensitivity to the public budget, which we define as the legitimate instrument of the government's power to spend and to collect revenue, with the concept of "common wallet perception". It would only be possible to clarify this concept by evaluating the psycho-social factors that affect the attitudes and behaviors of people, whom are too versatile to fit into narrow schemes. Thus, the fact that the political, social and economic motives of people are open to social interaction necessitates a multi-faceted evaluation. Therefore, the main research question of our study is the psycho-social factors that explain why citizens do not show sensitivity towards their common wallets, as much as they show towards their personal wallets.

In this context, through mentioning psycho-social factors that affect (weaken or improve) public budget awareness, which demonstrates a formation and development process intertwined with society, the parameters that form the basis of society's attitude and perception on this issue are discussed from different perspectives. In the first part of this study in which we adopt this perspective, the concept of "common wallet" that we have used as a metaphor was explained and an evaluation was made on the weakening of the perception of "common wallet" in the public budget. In the continuation of the study, psychological and sociological factors that weaken public budget awareness are scrutinized by referring to the following concepts respectively: lack of social belonging (fiscal alienation), altruistic punishment (lack of fiscal altruistic punishment), bystander effect (fiscal bystander effect), social loafing (fiscal social loafing), the theory of cognitive dissonance (behavioral fiscal dissonance) and undeveloped ethical behavior/culture (the problem of fiscal ethic). And in conclusion, new psychological and sociological concepts related to public budget are added to the public finance literature.

\section{Weakening of "Common Wallet" Perception in Public Budget}

The government makes public expenditures while meeting the common needs and gets public revenues in order to realize these expenditures. Through these revenues, the goods and services necessary for the provision of public services are 
purchased and expenses are converted to public services. Therefore, we can express the public budget, which is the total of the expenditures made to meet the common needs of the society and of the revenues obtained to finance these expenditures, as a common wallet used for the common needs of the society. At this point, an important aspect is that this wallet is financed by the citizen and spent back on the provision of services to the citizen. This situation points to one of the important points where the personal wallet (budget) of the microeconomic actors (individuals and firms) and the common wallet (public budget) differentiate. In our study, based on these differences we preferred to express the public budget as a "common wallet" as a means of metaphor. At this point, we can define the concept of common wallet as follows: "It is a public resource that demonstrates the common income and common expenses of the citizen as a whole in a detailed way and provides the executive body with the authority to collect revenues and realize the expenses by using public authority and resources in line with the common interests of the society."

On the other hand, it is very important to evaluate all aspects of the concept of the common wallet, which develops and changes in a tightly coupled way with social dynamics. At this point, citizens' perception of the common wallet is an element that needs to be emphasized.

Although the concept of "common wallet" that we use through the metaphor exists in practice, it cannot be clearly understood due to some problems. The primary problem is that the citizens, who are the real owners of the resources that make up this wallet, are not aware that they are the owners, or that their awareness is weak. At that point, the weakness or weakening of perception will bring along some problems such as not using the resources correctly, loss of social sensitivity and awareness, and disruption of the audit process. An important factor in this undeveloped perception is that citizens do not show as much interest and responsibility towards the public budget, which is their common wallet, as they show towards their personal wallets. Therefore, it is not possible under these conditions to reflect social demands in public decision making.

Given the fact that the budget has political, economic, fiscal and legal consequences, it is clear how important it is to use it correctly and effectively. In this context, it is necessary to answer the question of "why citizens do not show the same sensitivity as they show towards their personal wallets when the public resources are not used correctly and efficiently", which is the starting point of our study. At this point, there are many factors that weaken the perception of common wallet. These elements can be listed as insecurity of law, corruption, media-trade-government relationship, the effect of liberal thought, the structure of civil society organizations, lack of publicity awareness, weakness of the awareness of citizenship, the role of education, psychological and sociological elements. However, in this study, we evaluated psychological and sociological factors. 


\section{Psychological and Sociological Factors}

The mainstream thought system defines individuals as homo-economicus. In other words, according to the basic assumption of classical and neo-classical economics, individuals are rational and selfish. Therefore, since individuals are rational in their decisions and choices, they do not reflect their moods, emotions and behaviors. However, people are too versatile to fit into such narrow schemes. In fact, the human is a social being that influences and is influenced by the society in which $s /$ he lives. Therefore, people are open to social interaction. This social interaction affects people's attitudes and behaviors. For this reason, people often behave in a similar way by being influenced by each other despite their personal differences. Besides, this situation affects the motives of the political, social and economic nature. Therefore, it would be appropriate to use some sociological and psychological concepts in explaining the formation and development process of the perception of common wallet, which is intertwined with society.

Indeed, this part of our study is included in the scope of behavioral economics, which is a separate field of study. As a matter of fact, behavioral economics refers to an area that observes the effects of people's attitudes, behaviors and thoughts on economic-based choices and decisions and examines these observations grounding on experiments (Toigonbaeva \& Eser, 2011: 288). Thus, when the weakening of individuals' common wallet perception is examined within the framework of behavioral economics, the following concepts emerge.

\subsection{Lack of Social Belonging (Fiscal Alienation)}

Belonging is a concept that brings the understanding to the fore in human relationships. In fact, in terms of the word meaning, it is defined as relatedness, affiliation, and belonging. As an expression of a developing bond in the individualsociety relationship, belonging also makes it easier to understand people in similar categories. Therefore, belonging can be expressed as a reflection of a state of consciousness. In this context, a sense of belonging is considered as a prerequisite for the ability to develop collective consciousness, the productivity in meaning-making and the emergence of social elements such as value, norm, and identity. Belonging can be expressed as part of the process of social integration. Thus, people gain a sense of belonging by virtue of their social environment, while at the same time, they can gain this sense through their conscious choices throughout their lives. In other words, while the sense of belonging can be shaped by the social environment acquired by birth such as ethnic identity, family, religion and nationality, it is also possible to shape it later by conscious choices such as education, politics, economic and social environment. This reveals that the concept of belonging is not one-dimensional. For this reason, the necessity of interdisciplinary cooperation comes up in explaining the concept of belonging. In fact, people establish social relations and maintain their lives, in the context of multi-dimensional intellectual and action-based relations which bear the traces of their personal identities and appearances such as socio-cultural, psychology 
and economy. This explains, in one aspect, why people exhibit similar attitudes and behaviors in social groups despite individual differences (Alptekin, 2011: 20-21).

Ensuring social integration is in direct proportion to how much people feels the sense of belonging for the society in which they live. On the other hand, social integration has a very important position in terms of the development of the sense of "we" and social consciousness. However, people have turned away from social integration with the strengthening of institutional structures shaped in the context of transfigurations and transformations occurring in today's conditions. Especially after the 1980s, spotlighting of the individualization has accelerated this process.

On the other hand, with the discourse of "modern man", social structures have lost their meaning and reality and under these conditions, people have become under the influence of sudden and temporary popular culture. According to Zijderveld (1970), human beings have become an expert attendant as a means of the consumption patterns determined under these conditions. For this reason, people have been alienated from themselves and from society. In other words, people do not regard themselves as an element contributing to the formation of social structure.

The detachment or estrangement of people from society is associated with the concept of alienation. The concept of alienation is a broad concept that can be reduced to the beginning of life. However, we will mostly focus on the evaluation of the alienation concept in the context of social psychology. In this context, Georg Wilhelm Friedrich Hegel (1807/1998) was the first to address the concept of alienation. In his early works, Hegel considered the concept of alienation as a result of private property. According to Hegel (1807/1998: 294-297), people live in a world which they shape in the direction of their labor and knowledge. However, as a result of the existence of rules in this world, which prevent people from fulfilling their basic needs, people feel themselves alien. People's working in order to satisfy their needs has turned nature and the objects in nature into objects that they use for their own needs. Unlike Hegel, Marx (1961/2007) contextualized alienation as an outcome of the social world rather than a cause of it. According to Marx (1961/2007: 142-172), the objectification of the products that people obtain as a result of working in the capitalist system, that is, becoming independent of themselves, leads to alienation. In other words, alienation will occur if the products of people's labor become a force against them or bring them under control. Therefore, according to Marx (1961/2007: 67-83), objectified labor alienates man from nature, from his/her self, humanity, life activity, from the products of his/her activity and from his/her body. This situation, on the other hand, causes people to stop being a conscious being. According to Weber, alienation occurs under the influence of economic, social and political forces. Weber also determined the interaction field of the concept of alienation in this framework. Besides, in addition to Marx's idea of the alienation of the workers from their labor, Weber also stated that the soldiers become alienated from violence and the sellers and professors from their works (Yalçın \& Dönmez, 2017: 153).

The concept of alienation, which causes weakening of social connections, has been discussed within the scope of powerlessness, meaninglessness, normlessness, 
isolation and self-alienation dimensions, by Melvin Seeman (Seeman, 1959: 783). Alienation, in one aspect, is related to the formation of the "powerlessness" situation, which is associated with people's feeling of inability to influence and direct the society in which they live. This situation occurs in humans in consequence that they cannot achieve the goals they want to achieve (Seeman, 1959: 784). According to Seeman, the sense of powerlessness also affects individuals' getting information from their environment and concentrating on that information. As a result of his study conducted on Swiss university students, Seeman observed that students do not want to acquire knowledge about nuclear energy and make any effort in this direction, on the basis of the idea that they have no control over nuclear energy (Yalçın \& Dönmez, 2017: 157).

"Meaninglessness", which is accepted as another dimension of alienation, stems from the inability of people to ascribe meaning to their own activities due to managerial inefficiencies. Meaninglessness increases when individuals do not know what to believe or when the decision-making process is not clear. It is because individuals have difficulty in understanding the situations they cannot foresee (Seeman, 1959: 786).

Normlessness, which is accepted as another dimension of alienation, on the other hand, is defined by Seeman as believing in the necessity of behaving in ways that are contrary to the framework envisaged by the society in order to reach a certain goal (Yalçın \& Dönmez, 2017: 157; Seeman, 1959: 787).

The "isolation" dimension of alienation emerges when individuals do not adopt common values and goals that are socially accepted. Therefore, individuals who are isolated from society or who isolate themselves from society will be estranged from the standards of society. At this point, Seeman emphasizes that the dimensions of normlessness and isolation differ from each other in terms of means and objectives. Normlessness refers to the situation of using any legal or illegal means while accepting the objectives and acting in this direction; isolation, on the other hand, refers to the situation in which the objectives are not accepted (Yalçın \& Dönmez, 2017: 157).

Self-alienation, which is the last dimension of alienation, is defined as a kind of experience in which an individual regards himself/herself as a stranger. Individuals move away from engaging in rewarding actions that will make them achieve real satisfaction. Therefore, instead of the accomplished actions, they focus on the rewards which will be achieved as a result of these actions (Seeman, 1959: 790). Seeman exemplifies self-alienation with the situation of a painter who paints considering the profit to be obtained from the sale of the artwork, rather than the artwork itself (Yalçın \& Dönmez, 2017: 157-158).

Considering all these evaluations, we can say that social exclusion will come to the fore in social structures where social belonging is weak or undeveloped, with the influence of the alienation dimension instead of social integration. Upon being exposed to social exclusion, people's inadequacy to create their own future or inability to reach these opportunities will affect many political, social and economic factors. In fact, this constitutes a mass of individuals who lack citizenship rights and whose social 
connections are weak. On the other hand, it is an unchangeable reality that public administration mechanisms as a whole cannot be evaluated separately from social processes and formations. In this context, these forms of formation lead to the weakness or weakening of the perception of the common wallet created by the common contributions of the society. This situation can also be called "fiscal alienation". As a matter of fact, it is very difficult to create or perceive common values in social structures where social perceptions cannot be nourished. It is because this situation will also lead to a case of social weakness in which social empathy remains weak while individualization gains strength and alienation increases, in society. Therefore, social belonging is accepted as one of the basic elements of social integration. In fact, social belonging and integration require a sense of "us" rather than a sense of "I". Therefore, the development of a sense of social belonging will contribute to the development of citizens' sense of responsibility at many different points, especially in the public sphere.

\subsection{Altruistic Punishment (Lack of Fiscal Altruistic Punishment)}

Altruistic behavior refers to the situation in which the person does not expect an award or a personal benefit from the altruist act performed. Indeed, altruism is also defined as prosocial or altruistic behavior in general in the literature (Karadağ \& Mutafçılar, 2009: 43).

Altruistic punishment means that individuals punish other individuals if they know that the results will cause any negativity for themselves or the group they are in and although they know that this situation will not provide them with any financial benefit. The possibility of altruistic punishment depends on the motives of trust and integration within the group (Fehr \& Gachter, 2002: 137). On the other hand, the maintenance of cooperation throughout human history reveals the necessity of applying altruistic reward and altruistic punishment (Güney \& Bahçekapıll, 2010: 30).

Altruistic punishment can be considered as an indicator that the maintenance of behaviors in accordance with the norms of justice is important in the social groups. However, the important point here is that when people inflict altruistic punishments, they should base or adopt social norms and values, not individual interests or pleasures. On the other hand, we can say that for people social preferences gain importance besides economic preferences (Barclay, 2006: 342). In this context, it would not be wrong to say that collective actions can be controlled by altruistic ways of behavior. It is because the punishment of behaviors that will harm the group by individuals within the group, that is, reacting to the attitudes and behaviors that will harm the group, will create pressure for those who do the harm, and this will be a disincentive.

Reacting to or punishing the attitudes and behaviors that harm the social group by the members of the same group will create an internal control mechanism. However, the person who reacts to the harm that occurs must also run the risk of a counter-reaction or exclusion. For the extent of the reaction to and exclusion of these 
people to be large often condemns society to remain unresponsive. The existence of the obstacles against acting with social consciousness for the one who reacted can distract him/her from this behavior pattern. In this context, we can say that the society will be unresponsive to the lawlessness, corruption and injustices that will be experienced in the political, social and economic fields in the social structures where these obstacles emerge or where altruistic punishment remains weak. On the other hand, in social structures where social responsibility and integration are not developed, people can act just for the sake of not violating group norms. In other words, people just avoid behaving against the group without adopting common social values. In this case, people will exhibit these behaviors in areas where they will not be subjected to reaction or punishment. Therefore, it is very important for people to adopt common social values. In this context, it is very important for the common wallet, which can be characterized as one of the common values of the society, to be adopted as a common value. These elements play a decisive role in the development or weakness of the perception of the common wallet. From the perspective of public finances, we can call this situation which weakens public budget awareness and sensitivity as the "lack of fiscal altruistic punishment". Altruistic punishment, which we consider as an internal control mechanism, in one aspect, is also important in the framework of the protection of the public sphere and rights. Exclusion of unethical forms of behavior taking place in the public sphere (such as corruption, bribery, nepotism) and the people who exhibit these behavior patterns in social groups will establish social consciousness. Otherwise, within the process, unethical behaviors can be normalized in social structures that become unresponsive.

\subsection{Bystander Effect (Fiscal Bystander Effect)}

The murder of Kitty Genovese which occurred on March 13, 1964, in the Kew Gardens district of Queens, New York, has long been featured in the press and has been the subject of many discussions. As a result of the discussions which reflected also in the field of psychology, many studies have been conducted and this psychological-based event has been called the "bystander effect" by John Darley and Bibb Latane. The murder of Kitty Genovese occurred as follows: Kitty Genovese was beaten, stabbed and raped by a knife-wielding attacker very close to home on her way home after work. Genovese was taken to the hospital upon the arrival of the police. However, Genovese died on the way to the hospital. According to the first reports, 38 people witnessed the attack lasting more than half an hour and no one did anything to prevent the murder. It was then reported during the course of the trial that there were 12 neighbors who heard and saw the crime. After the event, social psychologists, researchers, and journalists have directed to the factors underlying the insensitivity and selfishness of the people. Social psychologists have argued that no one intervenes in the event due to factors such as the diffusion of responsibility and pluralistic ignorance with reference to the presence of many witnesses. In fact, similar results were obtained in later psychological-based studies (Sagarin \& Lawley-Sagarin, 2005: 167). 
After the murder, individuals who noticed the events that took place in the society but remained unresponsive to these events were characterized as the bystanders. The bystander effect is defined as the individuals' only watching the occurrence of an event and influencing other individuals by causing them to watch without interfering (Özdevecioğlu, Kaya \& Dedeoğlu, 2014: 28). The bystander effect is also referred to as audience effect or bystander apathy.

The studies carried out on the bystander roles divide them mainly into two as constructive and destructive. Apart from this main distinction, bystander roles were detailed in the forms of abdicating, avoiding, instigating, manipulating, collaborating, facilitating, intervening, defending, empathizing, sympathizing, and succumbing (Paull, Omari, \& Standen, 2012: 360-361). In this context, bystander apathy is a concept stating the situation in which people feel less responsible as the number of people who realize the event increases and therefore expect others to intervene (Hudson, Bruckman, 2004: 169). In other words, people's reactions to the events taken place inversely proportional to the number of group members (Fredricks, Ramsey, \& Hornett, 2011: 4).

Social pressures (one's thinking that $s /$ he will do something wrong and, avoiding it), pluralistic ignorance (one's complying to the inaction of others in social harmony, thinking that it is not his/her business), the diffusion or sharing of responsibility (the belief that others will intervene), the desire to protect oneself by believing that his/her security is in danger, one's thinking that he/she does not have the sufficient skills (perceived inadequacy) and, the complexity of the situation are considered among the reasons of the bystander apathy (Özdevecioğlu et al., 2014: 28; Grantham, 2011: 264).

Diffusion of responsibility is an important concept that is counted as one of the reasons for the bystander apathy. The concept of diffusion of responsibility was first introduced into literature by John Darley and Bibb Latané in 1968. The concept of diffusion of responsibility means that people feel less responsible for the behavior they exhibit within the group than for the behaviors exhibited individually (Forsyth, Zyzniewski \& Giammanco, 2002: 55).

In fact, one of the main factors underlying the desensitization towards social problems is the diffusion or sharing of responsibility. People think that the responsibility to intervene is shared within a society. In this case, people remain unresponsive, thinking that others will intervene somehow. Thus, as the number of people increases, the intervention rate decreases. Besides, they become in a dilemma as to whether there is really a situation that necessitates them to intervene. We can say that as the number of people who notice the event increases, they feel less responsible and therefore expect others to intervene. The case that everyone thinks someone else will intervene creates unresponsiveness. Thus, the reasons for insensitivity toward social problems are also explained by the concepts of the bystander effect or bystander apathy. Psychological-based bystander apathy can be said to affect people's perceptions of the common wallet in the context of the public budget. As a matter of fact, citizens may think that decisions made, or expenditures 
realized concerning the public budget have already been followed by someone else or it will be reacted against any negativity. In other words, citizens may move away from the perception of common wallet with the idea that responsibility is shared within a society. Therefore, the situation that, with respect to the ownership of the public budget, people feel less responsible for the budget as the number of citizens increases, and hence expect others to intervene in case of misuse of the budget, can be called the "fiscal bystander effect".

\subsection{Social Loafing (Fiscal Social Loafing)}

The link between social loafing and group performances was first demonstrated in 1927 as a result of the research conducted by Ringelmann (Kravitz \& Martin, 1986: 936). Ringelmann, in his study called rope pulling test, stated that the effort levels of individuals were different in a group or alone. Ringelmann, the first to report the reduction of individual efforts within a group, measured the force exerted by the workers in a rope pulling experiment involving German workers. The workers were included in the rope-pulling experiment alone and in groups of different sizes. Workers who participate were asked to pull the rope as hard as possible. During the experiment, a strain gauge was used to measure how much force a person applies when pulling a rope. The force exerted by the group members on their own was expected to increase based on the increase in the number of people. However, the result of the experiment was strikingly different. According to the reports held during the experiments, the individuals pulled the rope alone with an average force of $63 \mathrm{~kg}$. In groupings of three, the total force exerted by the individuals was limited to a force of $160 \mathrm{~kg}$, which is only two and a half times the individual performance. In the groupings of eight, the total applied force was measured as $248 \mathrm{~kg}$, less than four times the individual forces. As a result of the experiment, it was reported that the force applied to the rope per individual within the group was less than the force applied alone. Although Ringelmann did not perform this experiment in order to compare individual and group performances, he concluded that the force exerted by individuals decreased with increasing group size. The difficulty of determining the performances within the group has been shown as one of the most important reasons for this result and the concept of social loafing has been used for the first time. The fact that individuals tend to show less effort within the group is called the Ringelmann effect (Latané, Williams, \& Harkins, 1979: 822-823).

Ringelmann effect is important because it contains different results from common stereotype and social psychological theory. Indeed, according to the common stereotype, the sense of participation in the group leads to an increase in the effort. From this point of view, the moral integrity of the group and the effort to reach common goals trigger a sense of unity. The social psychological theory states that performance should be facilitated by the existence of dominant tendencies and simple and well-learned tasks involving the presence of other individuals. Therefore, it should be investigated whether the Ringelmann effect will occur in connection with other tasks. On the other hand, the Ringelmann effect has led to the generation of different 
fields to evaluate the social impact theory. In addition, if the Ringelmann effect is not limited to rope-pulling and represents a general phenomenon, it paves the way for research on when and why collective efforts are less effective than individual efforts (Latané, Williams, \& Harkins, 1979: 823). In fact, studies conducted in this field have shown that social loafing is valid in various tasks and groups (Karau \& Hart, 1998: 186187). Given that many parameters have an impact on the attitudes and behaviors of individuals, it is clear that these parameters will also affect collective action productivity and consciousness.

The concept of social loafing, which has started to be used upon Ringelmann's rope pulling test, indicates that individuals tend to be less productive or reduce their efforts when they are compared to others in a group (Harcum \& Badura, 1990: 629). Social loafing arises when people consciously or unconsciously make less effort in a group than they are alone because of a decrease in social consciousness (Liden, Wayne, Jaworski \& Bennett, 2004: 286).

Social loafing is also called social idleness or social parasitism in some sources. The reasons underlying social loafing behavior can be listed as follows: individuals' thinking that the effort they spend in the group will be disregarded, that other individuals in the group will exhibit loafing behavior, and therefore aiming to achieve equality with other individuals by reducing their efforts and their thinking that the gap will be compensated by others if they do not fulfill their duties. (Doğan, Bozkurt \& Demir, 2012: 58). On the other hand, some research results show that the level of social loafing has changed due to differences in internal and external factors (Bolin, \& Neuman, 2006: 566).

The concept of social loafing has been the subject of many researches over time. For this reason, many theories and models have been developed regarding the concept. One of the leading theories, social impact theory that put forward by Latane in 1981 focused on the possible causes of social loafing. According to this theory, people constitute both the source and the target of social impact. The level of social impact as a result of a situation is related to the power, importance and number of existing sources and targets (Karau \& Williams, 1993: 682).

The social impact of group dynamics on the individual has three consequences. The first is that the group dictate their opinion and decisions to the individual by putting social pressure on the individual. The second is that, despite everything, individuals act against the group in direction with their own opinion and decisions. The last one is that individuals adopt the group's opinion and decisions, values, beliefs and behavior norms and comply with the group (Silah, 2000: 183-184).

It should also be noted that the phenomenon of social loafing is valid for the cognitive, physical, and perceptual endeavors under the conditions we mentioned. In fact, there are theories that contradict the concept of social loafing (Taner \& Isin, 2017: 31 ). On the other hand, we can say that the groups have a promoting or inhibiting impact on individual attitudes and behaviors. In fact, if the attitudes and behaviors of the individual comply with the group norms, these attitudes and behaviors are 
promoted by supporting them. Otherwise, they are inhibited. The individual remains under pressure from many sources while showing compliance behavior. The existence of social loafing within the group causes the members of the group to be disappointed, makes the members less productive and leads to low participation in the group (Harkins \& Petty, 1982: 1216-1217).

In this context, we can say that some citizens exhibit social loafing behavior regarding keeping track of the common wallet created by joint contributions. Although individuals contribute to the formation of the common wallet, they may choose to make less effort to act in line with social goals, due to the reasons underlying social loafing. In fact, when citizens think that the efforts they made towards their works regarding the common wallet will be disregarded, they will tend to loaf. At the same time, when they think that other citizens will exhibit loafing behavior in return for their efforts, it causes them to reduce their efforts in order to even up with others. Therefore, individuals' exhibiting the social loafing behavior and remaining unresponsive in case of misuse of the public budget can be called "fiscal social loafing". That all citizens have a perception of common wallet is very important in terms of the conservation of this wallet. Another reason underlying fiscal social loafing behavior is the decisions of individuals regarding that the efforts they will make are not necessary and important. On the other hand, the social impact is very important because the perception of the common wallet of the citizens can vary with the emotions, reactions, impulses, beliefs, cognitions and behaviors of other individuals. Besides, not identifying citizenship awareness with the efforts to conserve a common wallet may cause their efforts to remain weak and cause them to have low motivation. This situation is more frequently observed in social structures where social integration and common values were not formed.

\subsection{The Theory of Cognitive Dissonance (Behavioral Fiscal Dissonance)}

The cognitive dissonance theory put forward by Leon Festinger in 1957 expresses the situation in which one's knowledge, beliefs or attitudes contradict another knowledge, beliefs or attitudes of the same person. One will be inclined to eliminate the existence of this contradictory situation by eliminating contradictory cognitions, i.e. by acquiring non-contradictory cognitions or by diminishing the importance of contradictory cognitions. The cognition we use here expresses the information elements that individuals have about their attitude, behavior, and environment (Festinger, 1957: 177-179).

The theory of cognitive dissonance, which is one of the dissonance theories, can be likened to the case of an individual's developing a psychological defense mechanism. For example; "Smoking causes lung cancer" and "I am a cigarette addict" are two cognitions with contradictory information. Moreover, this contradiction is not logical, but psychological. According to Festinger's theory of cognitive dissonance, the existence of such cognitive dissonances distresses people. Therefore, people act in accordance with the motive to get rid of this dissonance. Therefore, to reduce the 
existing cognitive dissonance, it is necessary to reduce the number of dissonant cognitions or to increase the number of harmonious cognitions. Namely, in the previous smoking example, we can include some harmonious cognitions in accordance with this situation in order to reduce cognitive dissonance. For example, we can weaken the cognition regarding that smoking causes lung cancer, by strengthening the cognitions of "smoking calms my nerves", "I am accepted in the group it is involved", "I smoke but I also do sports", which are harmonious with each other. Another way to reduce cognitive dissonance is by rejecting the opposite cognitions. For example, conflicting cognitions can be rejected by acquiring cognitions such as "air pollution is just as harmful as smoking", "doctors are also smoking" or by avoiding reading articles stating that cigarettes are harmful to health. However, as a result of a decision made or an action realized by a person, if the inconsistency between the person's behavior and the cognition that contradicts this behavior is caused by oppression, cognitive dissonance will not occur. Thus, one will not need to convince himself/herself on the rightness of his/her behavior. On the other hand, in the case of the presence of cognitive dissonance, the person will tend to change his/her behavior using a subjective justification, if $\mathrm{s} /$ he cannot find an objective justification for which $\mathrm{s} / \mathrm{he}$ can explain or justify his/her behavior. In other words, one will attempt to explain his/her behavior by changing his/her attitude (Kağıtçıbaşı \& Cemalcılar, 2014: 168-170).

The cognitive dissonance theory, which is used in many different disciplines, is a theory that we can use in explaining why citizens remain unresponsive or insensitive to corruption and the inefficient use of the common wallet. Citizens, as voters, participate in the decision-making process by voting. Citizens, thus, make a selection and decide, through voting. After this decision is actualized, the person tends to increase his/her love for the political party organization $s /$ he chose by voting within the voting mechanism and to decrease his/her love for the ones s/he did not choose. In fact, the person, here, tries to develop a psychological defense mechanism and internalize the decision $\mathrm{s} /$ he made. Therefore, in case that the political party organization, for which they vote, is in power, even though they realize that there is a wrong application, decision or any unethical behavior within this direction regarding the common wallet constituted by their contributions, they try to legitimize the actions in their minds by changing their attitudes. In other words, people try to internalize their political preferences in an effort to explain their behavior by changing their attitudes. However, if the political party organizations, which they did not vote for, exhibit the same attitudes and behaviors, the strongest response to them will be shown by these people. Therefore, individuals try to comfort their own consciences by justifying their own attitudes, behaviors and the opinions they defend, psychologically in this way. In other words, even if people are aware of the unacceptability of unethical actions, they try to convince themselves that they are "acceptable" because of the circumstances they are in. These attitudes and behaviors of individuals are evaluated within the framework of cognitive dissonance theory and can be called "behavioral fiscal dissonance". Thus, the phenomenon of behavioral fiscal dissonance is one of the important reasons for the weakening of the perception of common wallet. 
However, the fact that cognitive contradictions (behavioral fiscal dissonance) do not occur at the same rates in every culture should be taken into consideration. In fact, independently of cultures, people do not perform all their attitudes and behaviors just for the sake of getting rid of cognitive dissonance (Kağıtçıbaşı \& Cemalcılar, 2014: 174). In this context, cognitive dissonance was evaluated only as a variable relevant to the subject.

\subsection{Undeveloped Ethical Behaviors/Culture (The Problem of Fiscal Ethic)}

Ethical behavior/culture is a multifaceted phenomenon that affects social structures and institutions with its political, social and economic dimensions. Indeed, ethical behaviors/culture is defined as the orientation of individuals towards good and right behavior while making decisions. Ethical behaviors/culture are important behavior patterns that shape people's lives. In this context, the issues regarding what is good or right for people and social structures fall within the scope of their ethical behavior/culture. Public administration ethics, on the other hand, is that employees within a certain organizational structure shape their behavior patterns within the framework of determined laws, ethical codes and various rules (Özdemir, 2008: 182).

On the other hand, many political-, social- and economic-based societal changes have taken place in certain periods throughout history. That changes occurred in these periods and ethical values and behaviors/culture do not develop together creates a gap. As a matter of fact, it was observed that unethical behaviors (corruption, bribery, blackmail, smuggling, abuse) increased during periods of this gap (Eryılmaz, 2008: 5).

Ethics is the transfer of any theory into practice, its reflection on the rules of conduct or its implementation. Therefore, the moral collapses experienced as a result of the neoliberal globalization process attract attention as well as ethical behaviors (Yüceol, 2013: 14). This process has led to an increase in income inequalities, oppression on labor markets and the growth of hazards on the common values and environment. The fact that the globalization process moves in the direction towards the developments aimed at increasing capital accumulation increased the gaps in income distribution. This situation paved the way for the emergence of many socioeconomic problems, especially unemployment and poverty. On the other hand, underdeveloped countries, where income distribution inequalities are constantly increasing, have been exposed to bloody wars and divisions through experiencing divergence over religion, ethnicity and culture prominently (Yüceol, 2013: 79-80). The existence of capital movements, which are the driving force of the globalization process according to which all seems fair in the way to increase the profits, has increased the moral concerns in terms of human values. This process indirectly damages the development of ethical behaviors/culture.

On the other hand, ethical values, principles and rules are the gains that develop in a specific way to social structures. Moreover, ethical issues can arise not only in the context of politics, judiciary and public administration, but in all areas of 
social structure. The suffering of social ethics from erosion also affects other social and institutional areas. The main problem with ethics is that the criteria for determining what is ethical and what is unethical have started to be lost, or that people become desensitized to this situation. Public administration ethics, on the other hand, is also important due to the fact that public officials bear the responsibility to citizens and the public interest is taken as a basis. Therefore, these officials must take into consideration that they have social responsibilities when making decisions and conducting services (Eryılmaz, 2008: 6-8).

In this context, while undeveloped ethical awareness and culture cause the spread of unethical behaviors (such as corruption, nepotism, bribery) in society, these adversities are reflected in other social areas as well as in the public administration process. This situation adversely affects the development process of common wallet perception. The situation, which can be called "the problem of fiscal ethic", is valid for both public officials and citizens. It is because public officials do not only bear responsibility for the organizational structure in which they work, they are also responsible to the citizens. For this reason, the adoption of ethical consciousness and ethical culture values by the public officials involved especially in the implementation process of the decisions taken within the decision-making mechanism regarding the budget, which is created by the contribution of the citizens, is important. Structure, practice and rules that support ethical behavior/culture should be encouraged. In addition, it is quite important to support ethical elements through legal arrangements made within the legal framework, to increase the participation of the public to the process, to increase the functionality of the audit mechanism, to carry out studies in all areas of life for raising awareness of ethical values and spreading the ethical culture (Eryılmaz, 2008: 9).

Nevertheless, the internal dynamics and structural characteristics of each social structure differ. Therefore, the rate of development of the ethical behaviors/culture and the approaches, perception levels and other factors regarding these behaviors/culture develop and change, in ways peculiar to each society. However, public administrations certainly have responsibilities towards citizens in every society. Therefore, the development of ethical awareness and the adoption of ethical culture emerges as an important element in every social structure.

Sen (1990) states that modern economics has two main starting points related to engineering and ethics. One of the most important works is On Ethics and Economics (1990) which has critique of utilitarianism. This work examines how utilitarianism as a deeply rooted ethical thought affects economic theory and welfare economics. According to Sen, it is always open to criticism to consider the same as welfare and benefit. Furthermore, the claim that valuable is merely welfare is not an acceptable argument (Sen, 1990: 46). The standard propositions of modern welfare economics are based on both the personal interest-based behavior and the benefitbased social success (Sen, 1990: 30). But it is unethical to argue that everything except the maximization of personal interest is irrational (Sen, 1990: 15). 
On the other hand, in order to make sense of the "good" and "right" adopted by societies, it is necessary to aim at the moral philosophy that includes what these concepts mean. Differences in the views of what is good or right are evaluated within the framework of ethical theories. As a matter of fact, it is important to point out whether the moral approach we adopt in the ethical context is a utilitarian morality or a principled morality (Haşlak, 2006: 186-187).

\section{Conclusion}

Meeting the common social needs, which we consider as one of the main reasons for the existence of the state, is possible by realizing the use of public resources, which are co-financing instruments. Therefore, the public budget, which we characterized as the common wallet, appears as a multi-dimensional concept that shapes social structures. In this context, the psycho-social elements that shape the individual-society dynamics that we have discussed in our study make it easier for us to evaluate the factors that affect public budget awareness which we characterized as a common social value.

As a matter of fact, fiscal mechanisms shaped by social interaction patterns cannot be subject to an evaluation that is independent of common social values and aims. This also stems from the fact that people influence each other with social behavior patterns, in other words, people are social beings. For this reason, the factors that weaken the perception of the common wallet (public budget awareness) by utilizing psychology and sociology are investigated. In this context, the concepts of fiscal alienation, lack of fiscal altruistic punishment, fiscal bystander effect, fiscal social loafing, behavioral fiscal dissonance and the problem of fiscal ethic are introduced to the public finance literature.

The lack of a multi-dimensional assessment of the attitudes and behaviors of the citizens positioned at the center of the fiscal decision-making processes makes it difficult to formulate qualified economic policies. Therefore, the examination of social structures and fiscal processes by using psycho-social elements that evaluate people's attitudes and behaviors through different dimensions is very important for the development of public awareness and public budget awareness.

\section{References}

Alptekin, D. (2011). "Toplumsal Aidiyet ve Gençlik: Üniversite Gençliğinin Aidiyeti Üzerine Sosyolojik Bir Araştırma", Doctoral Dissertation, Selçuk University Social Sciences Institute, Konya.

Barclay, P. (2006). "Reputational Benefits for Altruistic Punishment", Evolution and Human Behavior, 27(5), 325-344. 
Bolin, A. U. \& Neuman, G. A. (2006). "Personality, Process, and Performance in Interactive Brainstorming Groups", Journal of Business and Psychology, 20(4), 565-585.

Doğan, A., Bozkurt, S. \& Demir, R. (2012). "Sosyal Kaytarma Davranışı Ile Algılanan Görev Görünürlüğü Arasındaki ilişkinin İncelenmesine Yönelik Bir Araştırma", Sosyal Ekonomik Araştırmalar Dergisi, 12(24), 53-80.

Eryılmaz, B. (2008). "Etik Kültürü Geliştirmek", Türk Idare Dergisi, 459, 1-12.

Fehr, E. \& Gächter, S. (2002). "Altruistic Punishment in Humans", Nature, 415(6868), 137-140.

Festinger, L. (1957). A Theory of Cognitive Dissonance, Stanford University Press, California.

Forsyth, D. R., Zyzniewski, L. E. \& Giammanco, C. A. (2002). "Responsibility Diffusion in Cooperative Collectives", Personality and Social Psychology Bulletin, 28(1), 54-65.

Fredricks, S., Ramsey, M. \& Hornett, A. (2011). "Kinship and Bystander Effect: The Role of Others in Ethical Decisions", Journal of Religion and Business Ethics, 2(1), $1-22$.

Grantham, T. C. (2011). "New Directions for Gifted Black Males Suffering From Bystander Effects: A Call for Upstanders", Roeper Review, 33(4), 263-272.

Güney, Ş. \& Bahçekapılı, H. G. (2010). "İnsanlarda Özgeci İşbirliğinin Psikolojik ve Beyinsel Temelleri", Türk Psikoloji Yazıları, 13(25), 29-38.

Harcum, E. R. \& Badura, L. L. (1990). "Social Loafing As Response to an Appraisal of Appropriate Effort", The Journal of Psychology, 124(6), 629-637.

Harkins, S. G. \& Petty, R. E. (1982). "Effects of Task Difficulty and Task Uniqueness on Social Loafing", Journal of Personality and Social Psychology, 43(6), 1214-1229.

Haşlak, ì. (2006). "Etik Kongresinin Ardından", Akademik Incelemeler Dergisi (AID), 1(1), 185-192.

Hegel, G. W. F. (1998). Phenomenology of Spirit, (Trans.) A. V. Miller, (Original work published 1807), Motilal Banarsidass, Delhi.

Hudson, J. M. \& Bruckman, A. S. (2004). "The Bystander Effect: A Lens for Understanding Patterns of Participation", The Journal of the Learning Sciences, 13(2), 165-195.

Karadağ, E. \& Mutafçılar, I. (2009). "Prososyal Davranış Ekseninde Özgecilik Üzerine Teorik Bir Çözümleme", Felsefe ve Sosyal Bilimler Dergisi, 8, 41-70.

Karau, S. J. \& Hart, J. W. (1998). "Group Cohesiveness and Social Loafing: Effects of a Social Interaction Manipulation on Individual Motivation within Groups", Group Dynamics: Theory, Research, and Practice, (3), 185-191.

Karau, S. J. \& Williams, K. D. (1993). "Social Loafing: A Meta-Analytic Review and Theoretical Integration", Journal of Personality and Social Psychology, 65(4), 681-706. 
Kravitz, D. A. \& Martin, B. (1986). "Ringelmann Rediscovered: The Original Article", Journal of Personality and Social Psychology, 50(5), 936-941.

Latané, B., Williams, K. \& Harkins, S. (1979). "Many Hands Make Light The Work: The Causes and Consequences of Social Loafing", Journal of Personality and Social Psychology, 37(6), 822-832.

Liden, R. C., Wayne, S. J., Jaworski, R. A. \& Bennett, N. (2004). "Social Loafing: A Field Investigation", Journal of Management, 30(2), 285-304.

Marx, K. (2007). Economic and Philosophic Manuscripts of 1844, (Trans.) M. Milligan, (Original work published 1961), Dover Publications, New York.

Özdemir, M. (2012). "Kamu Yönetiminde Etik", Uluslararası Yönetim iktisat ve İşletme Dergisi, 4(7), 177-193.

Özdevecioğlu, M., Kaya, Y. \& Dedeoğlu, T. (2014). "Kişilik Özelliklerinin İzleyici Etkisi (Bystander Effect) Üzerindeki Etkisinde Kontrol Odağının Rolü", Erciyes Üniversitesi Iktisadi ve Idari Bilimler Fakültesi Dergisi, 42, 25-40.

Paull, M., Omari, M. \& Standen, P. (2012). "When Is A Bystander Not A Bystander? A Typology of the Roles of Bystanders in Workplace Bullying", Asia Pacific Journal of Human Resources, 50(3), 351-366.

Sagarin, B. J. \& Lawler-Sagarin, K. A. (2005). "Critically Evaluating Competing Theories: An Exercise Based On the Kitty Genovese Murder", Teaching of Psychology, 32(3), 167-169.

Seeman, M. (1959). "On the Meaning of Alienation", American Sociological Review, 24(6), 783-791.

Sen, A. (1990). On Ethics and Economics, Basil Blackwell, Oxford.

Silah, M. (2000). Sosyal Psikoloji (Davranış Bilimi), Gazi Kitabevi, Ankara.

Taner, B. \& İştin, A. E. (2017). "Çalışma Ortamında Sosyal Kaytarma", Uluslararası iktisadi ve Idari Bilimler Dergisi, 3(3), 25-41.

Toigonbaeva, D. \& Eser, R. (2011). "Psikoloji ve İktisadın Birleşimi Olarak, Davranışsal Iktisat", Eskişehir Osmangazi Üniversitesi iktisadi ve Idari Bilimler Fakültesi Dergisi, 6(1), 287-321.

Yalçın, Ö. \& Dönmez, A. (2017). "Sosyal Psikolojik Açıdan Yabancılaşma: Dean'in Yabancılaşma Ölçeği'nin Türkçeye Uyarlanması", Ankara Üniversitesi Sosyal Bilimler Dergisi, 8(2), 150-175.

Yüceol, H. M. (2013). Ahlâki Ekonomi, Detay Yayıncılık, Ankara.

Zijderveld, A. C. (1970). The Abstract Society: A Cultural Analysis of Our Time, Doubleday, New York. 